\title{
Comparison of Intellectual Property Financing Between China and America
}

\author{
Aizhen Li \\ Program of Intellectual Property, School of Law, Boston University, Boston, United States \\ Email: laz1021@bu.edu
}

\begin{abstract}
IP financing, or the use of IP assets (trademarks, design rights, patents and copyright) to gain access to credit, is gaining increasing attention in IP circles. Multinational corporations as well as small and medium sized enterprise, are leveraging their IP assets in exchange for finance, and lending institutions around the world are increasingly extending their business to provide loans on the basis of IP. Intellectual property financing plays a significant role to solve the financing problem for a number of the small and medium sized enterprises. As one of the highly developed countries in the market economy, the financing of intellectual property in the United States tends to be mature. Based on the study of the financing of intellectual property in the United States, we can get a lot of inspirations and enlightenments from the social judicial experience of United States. This paper draws on the advanced experience of developed countries, and elaborates its enlightenment to China's intellectual property financing.
\end{abstract}

Keywords: Intellectual property, pledge financing, value assessment, insurance

\section{Introduction}

As a new type of financing mode, intellectual property financing plays a certain role in promoting the development of small and medium-sized enterprises. Especially for SME ( Small and medium enterprises) with high-technology and cultural creativity, these enterprises have some high-quality technological achievements, their scale is still limited due to lack of funds. In order to get more financial support, Intellectual property financing has become a typical method of SME financing. Intellectual property financing model started relatively early in the US, and it has gradually evolved a characteristic mode of IP financing, which is a market-oriented with government leading support and multiparty cooperation mechanism [1].

Under this model, the practice and operation of intellectual property financing in the United States have made great achievements. For example, Altitude Capital Partners is a US $\$ 250$ million private investment fund which invests in IP assets and IP-focused companies, covering patents, trademarks, copyright and royalty streams. The company works with individual IP owners, as well as small and large IP-holding companies. In February 2007, Altitude invested in DeepNines, a network security solutions provider with returns linked to repayment from DeepNines' IP proceeds and secured by the company assets. In April 2008, Altitude paired with Goldman Sachs \& Co. to invest US\$11 million in Intrinsity, Inc., a Texas-based IP technology company designing processor cores. According to the above situation, China can learn from the advanced experience of American intellectual property financing model and create a good financial market environment [2].

\section{Overview of Intellectual Property Financing Mode in the US}

As one of the developed capital markets in the world, the United States has a long history of financing related to intellectual property. In Acritical 9 of Uniform Commercial Code clarifies the provisions of "unified security rights" and clearly define the scope in terms of all related rights. Moreover, the clause clearly states that the establishment of a secured transaction on intangible property is valid. Therefore, many US companies have incorporated intellectual property pledge financing into one of the means of raising funds, making technology-based enterprises more efficient and convenient on dealing with 
financing problem.

In order to effectively enhance the competitive status of SME, the United States United States starts from two aspects to boost the IP financing ----- legislation and practice [3]. It has provided many projects supporting and tax incentives for enterprise innovation, and promulgated many legislations including the Small Business Investment Act and the Equal Opportunities Act. In the meanwhile, the US government also established the SME Authority to provide guarantee for intellectual property pledge financing business, and enact various policies to support the application of intellectual property and participated in the management of intellectual property. It attaches great importance to promoting the innovation of enterprise financing. In legal practice, the United States has not imposed too many restrictions on the types of pledge of intellectual property. The pledge of intangible assets and tangible assets can be combined to ensure the diversity of pledge financing. Moreover, the highly uniform security provisions make some special types of security equally applicable to intellectual property, such as floating charge. Intellectual properties as intangible assets are constantly upgraded. The floating charge guarantees that intellectual property is conducive to the stability of the value.

\section{The Enlightenment of American Intellectual Property Financing Mode}

\subsection{Improving the Quality and Conversion Rate of Patents}

According to the World Intellectual Property Index published by the World Intellectual Property Organization in 2017, the number of applications for patents, trademarks and industrial designs in the world reached a new high era in 2016, and China ranked first in all three fields. Although the amount of applications related to intellectual property in China is considerable, there is still a long way to go for China to be a powerful country of intellectual property. The lack of high-quality and rational intellectual property and low conversion rate of patents lead to unpredictable risks in intellectual property financing.

The US has also experienced a series of adverse effects caused by the low quality of patents. Therefore, the US Patent and Trademark Office (USPTO) has taken quality control measures of US patents in the review stage mainly including two aspects: First, USPTO established the relevant departments which controlled the quality of patent examination. For example, the Office of Patent Quality Assurance (OPQA) is committed to ensuring the highest quality in patent examination. To that end, the Office provides assessment and analysis of quality at the USPTO through work product reviews for compliance, clarity and best practices, defining and standardizing quality metrics and providing feedback to Technology Centers with respect to their reviews and training. Second, industry experts conduct expert review of specific patents by peer review to supplement examiner's deficiency and attract more peers through open-ended review to improve the integrity of information related to existing technologies. The USPTO successfully improved the accuracy of the scope of prior art through this method. Therefore, the State Intellectual Property Office of China (SIPO) should strengthen the control of patent quality through every stage of patent application, patent examination and the late patent invalidation. Especially, the SIPO should regularly train patent examiners and set up expert reviews to conduct a rigorous review of the inventions filed.

There are two reasons leading to low patent conversion rate in China. For one thing, Chinese enterprises have a lower proportion of patent ownership. The results of mega data survey show that the ownership of patents of private enterprises in China is about 30\%. Compared with the United States, the $100 \%$ patent occupancy rate of American enterprises has obvious advantages. In order to encourage scientific research institutions to industrialize scientific research results, the United States adopted in The Bayh-Dole Act sponsored by two senators, Birch Bayh of Indiana and Bob Dole of Kansas in 1980. Prior to the enactment of The Bayh-Dole Act, patents generated by government-funded research projects had been owned by the government. Complex examination and approval procedures lead to very few patented technologies in government funded projects, which can be industrialized. By 1980, the federal government had nearly 28,000 patents, but less than $5 \%$ of patented technologies had been transferred to industry for commercialization. With the enactment of Bayh-Dole, it permits a university, small business, or non-profit institution to elect to pursue ownership of an invention in preference to the government. The success of the Bayh-Dole is that through the cooperation of the government, scientific 
research institutions, and industry, they made joint efforts to effectively use the government-funded research and development results, thus accelerating the pace of industrialization of technological innovation results. With the combination of mature intellectual property protection system and commercialized management mode, the United States can invest quality patents with high value reward under the guidance of the market and exclude inferior quality patents from the market, which are the main factors for the diversified and better quality of intellectual property financing business in the United States. Therefore, in addition to encouraging innovation and patent application, China also needs to pay attention to optimize the overall structure of intellectual property and improve it on the basis of existing ones. Nowadays, many high-quality patented technologies are occupied by Chinese universities due to government's subsidies and research funding. The quality of patents applied by individuals and some enterprises is uneven, which makes the quality of intellectual property in pledge financing unable to meet the requirement of the financing market. China can refer to the US Bayh-Dole to transfer high-quality government investment patents to small and medium-sized enterprises and improve patent conversion rates so that they can be better commercialized.

The second deficiency is that more than $80 \%$ of SME in China apply for patents, but only $30 \%$ of them are invention patents. Lacking of adaptability, many patents are difficult to promote in the whole market and only meet the conditions of their own enterprises. However, the evaluation value of intellectual property is an important factor to determine its pledge financing. This evaluation should be combined with its commercial value, technical value and development value. If there is no market demand for patents, the high cost of conversion and the difficulty of technology implementation will lead to the decline of the overall value. The American intellectual property has obvious advantages in terms of quality of IP, more reasonable and stable structure, and higher commercial and development value in the market. However, according to the gradual transformation of China's economy, we believe that the quality of patents in China can be improved. [4].

\subsection{Optimizing the Government Evaluation Function}

In the process of building the IP financing model in the United States, there have been problems such as the strict review criteria of bank and low financing rate. In the risk management, banks are reluctant to provide financial support for intellectual property for the purpose of reducing the rate of non-performing loans, which makes it difficult to carry out financing related to intellectual property. In order to cope with this situation and reasonably avoid risks, plenty of enterprises and investors rarely pledge intellectual property with other tangible property in combination. To solve this problem, the U.S. government established the Small Business Administration (SBA), which was designated as a "permanent federal agency" by the U.S. Congress in 1958. It is committed to providing every aspect of services such as technical assistance, government procurement and financial support for small and medium-sized enterprises. SBA loans are made through banks, credit unions and other lenders who partner with the SBA. The SBA provides a government-backed guarantee on part of the loan. Under the Recovery Act and the Small Business Jobs Act, SBA loans were enhanced to provide up to a 90 percent guarantee in order to strengthen access to capital for small businesses after credit froze in 2008. The agency had record lending volumes in late 2010. SBA doesn't make direct loans to entrepreneurs to start or grow a business. Instead, it provides a guarantee to banks and lenders for the money they lend to small businesses owners. This guarantee protects the lenders interests by promising to pay a portion of the loan back if the business owner defaults on the loan. Essentially, SBA loans alleviate the risk associated with lending money to business owners and entrepreneurs who may not qualify for traditional loans - thus opening up lending opportunities to thousands of entrepreneurs, start-ups, growing businesses. The emergence of this institution provides the possibility of intellectual property financing for small and medium-sized enterprises, and greatly consolidated the construction of intellectual property financing mode. As a guarantor, government's credibility and guidance are guaranteed, which let banks to increase the bank's financing rate. Based on the guidance of the government, the financing business process in the United States is refined, and the risk control ability is strengthened. The government can even participate in the evaluation process of intellectual property. It is not difficult to find that the US government has strong guidance and adaptability in the initial stage of building the intellectual property financing system. After a series of market-leading, intellectual property financing has gradually developed into a competitive mechanism through market orientation. Among them, the 
government and banks play different roles in this process. Government plays a regulatory role, and banks control specific risks. With the continuous upgrading and updating of the intellectual property market, third-party evaluation agencies emerge as the times require, and gradually play a more important role than the backbone of government guidance [5].

Adhering to the superiority of the socialist system, China's banks are mostly state-owned, and the Chinese government's operability in guiding and evaluating intellectual property pledge financing is much higher than that of the United States. For example, at the end of 2009, in order to keep the real estate market healthy and stable, the government resolutely issued a series of policies including requiring the bank to raise the reserve ratio of deposits and other measures, to restrict the demand for speculative investment and purchase of houses, only to support the demand for self-employment. Through these policies, the real estate market pays more attention to the increase of quantity rather than irrational rise in price. In the same way, here, the government can optimize its own strength to evaluate and to protect the quality of intellectual property, then actively participate in the field survey of enterprises, and simultaneously do a good job in managing and guiding the financing system. In the corresponding special pledge financing, our government also needs to set up departments above, which is the provincial level in the basic system of risk pre-control, and actively carry out credit evaluation.

\subsection{Improving the Evaluation Mechanism}

China's intellectual property financing model is still in the initial stage of development and we also lack of uniform standards for patent value evaluation in the market. There are various methods of value evaluation for tangible assets, and the knowledge financing market is relatively chaotic. Traditional financing valuation methods include income evaluation method, cost evaluation method and so on. Due to the lack of obvious reference materials for intellectual property, the evaluation system of intellectual property in China is confused and inefficient because of the virtual value as the evaluation criterion. Neither academic research nor policy can be chosen as the best evaluation method. Governments, enterprises and investors often use the evaluation method of tangible assets to predict the market direction of intellectual property by integrating many factors, including market factors and policy factors. The evaluation system of intellectual property in the United States is relatively perfect, but it has not found a systematic evaluation method, relying on the market competition mechanism to eliminate the invaluable intellectual property patents. The establishment of evaluation mechanism is an important guarantee for defining evaluation value, reducing financing risk and improving the possibility of intellectual property financing. Therefore, China should optimize the structure of evaluation institutions to establish a comprehensive evaluation mechanism, and consider every aspect including cost assessment, market assessment, technological perfection, future development direction, patent life as the basis of evaluation, and acquire the final results of evaluation combined with market demand. Generally, compared with the historical cost and current market value of pledged intellectual property, banks are concerned about the realizable future value of intellectual property from the lending date to the maturity date of loans, and only the income approach evaluation can be used to calculate the future value. Income approach is a method of estimating the value of intellectual property through the discounted value of the excess income that intellectual property can create. The assessment of IP pledge financing should be based on an analysis of the applicability and limitations of traditional assessment methods in pledge IP valuation. According to the perspective of both parties, we establish the income present value method model. In order to achieve scientific and accurate evaluation results of this model, we can quantify and determine the three correction factors which are the spot value correction coefficient, the maturity liquidation value of the SME a set of indicator factors for the correction factor and the pledge financing risk factor through the combination of expert survey scoring and analytic hierarchy process and fuzzy AHP comprehensive evaluation method.

\subsection{Strengthening Risk Management of Financing}

As a green intangible asset, intellectual property has high added value. Exchanging and raising funds through intellectual property is of great significance for promoting enterprise innovation. In 1995, China recognized that intangible assets can be used as collateral, but the value of intangible assets is difficult to determine and usually accompanied by high financing risk, which has been criticized by the whole 
industry. Therefore, risk management of pledge financing is very important. As early as 2000, in order to help financial institutions as creditors on how to deal with intellectual property collateral, M-CAM Corporation of the United States has developed a mode that ensures the purchase price value of the IP collateral, and M-CAM company provides credit guarantee for seeking intellectual property financing opportunities. When a company finances a financial institution with its own intellectual property as a collateral, the mode allows the financial institution providing the loan to sell the intellectual property as a collateral to the M-CAM company at a predetermined price when exercising the security right. It is undoubtedly an effective choice to disperse these risks.

Insurance also is a tool to disperse the risks and reduce losses. It is a reasonable means of risk management under the conditions of market economy. Since intellectual property are intangible property which easily infringed compared with other commodities, and the scope of rights is not easy to determine. Therefore, they are vulnerable to infringement which will inevitably reduce the market value of intellectual property. In the process of technology research and development, enterprises also have the risk of infringing on patents of others. The cost of such infringement litigation in the United States has always been high, and once lost, the amount of compensation is also expensive, which has become a major problem that plagues intellectual property financing. Under this circumstance, the US insurance companies introduced intellectual property insurance. The rise of the insurance industry provides a great guarantee for the financing of intangible assets. In the late 1970s, many American insurance companies began to explore intellectual property insurance business in order to meet the demand of intangible property protection in the market. In 1973, the CGL (Commercial General Liability) of insurance services office Inc. in the United States included patent infringement liability insurance in the scope of general commercial liability insurance for the first time. The policy stipulates that insurance companies should bear corresponding insurance liability for damage caused by defamation, invasion of privacy, patent infringement and copyright infringement. After more than 40 years of judicial practice, the American insurance industry has developed rapidly. Currently, the most common intellectual property insurance in the United States is divided into IP liability insurance and IP enforcement insurance. Based on the guidance of the market, the insurance industry has accordingly entered the intellectual property financing market [6]. The main purpose of introducing insurance department is risk sharing and credit checking. Government departments and banks set standards for access to intellectual property financing for enterprises and evaluate joint insurance companies, then give feedback to enterprises' credit and operational capacity, and provide multiple safeguards for financing in the light of market demand for intellectual property. The United States has developed a sound evaluation mechanism for intellectual property financing. Through the division of different levels of enterprises, the amount of financing of different enterprises is defined. The classification system has a certain inhibitory effect on risk. [7]. In order to know the promotion of intellectual property financing insurance, banks can encourage SME to insure intellectual property financing insurance by giving preferential interest rates and lowering audit standards. After the joint assessment of the banks and the insurance companies, the appropriate amount of insurance is selected. When the pledgee is eliminated in the market competition and the loan cannot be recovered, part of the fund can be recovered through insurance claims, thus realizing the risk sharing between the insurance sector and the investment sector.

China's intellectual property insurance system develops relatively late compared with the US. At present, China does not have a complete and perfect insurance system to provide appropriate protection for the industrialization of intellectual property. In the early stage of the launch of intellectual property insurance, we can use government guidance model operation which better control of the market and accelerate the promotion of intellectual property insurance business. The government needs to implement relevant supportive policies for intellectual property insurance, then guide the development and implementation of new types of insurance and effectively reduce the rate to expand the market size.

\section{Comprehensive Strategy Analysis of China's Intellectual Property Market}

According to the development status of intellectual property pledge in China and the advanced experience of financing mode in developed countries, the following strategies can be drawn.

First of all, the quality is the basic guarantee to improve intellectual property financing. China should 
continue to improve and optimize the quality of patents through strict scrutiny of patent application, patent examination and the late patent invalidation. At the same time, it is also necessary to promote patent conversion rate according to some measures including transferring high-quality government investment patents to small and medium-sized enterprises. Government should consider giving policy support to intellectual property financing, and giving full play to the government's macro-control functions to achieve good communication between financing departments and enterprises which provide substantive guarantee for intellectual property financing of small and medium-sized enterprises. Secondly, China should participate in the risk management of intellectual property financing market, and build a sound risk control mechanism, then realize the scientific control of risk. Therefore, we advocate the IP insurance that is an effective tool for reasonable allocating the risk and also strengthen the research of information technology for applying different market risk assessment models to different intellectual property, and scientifically develop intellectual property financing business in the light of market trends.

In addition, the evaluation industry needs to establish standardized value evaluation methods through establishing a database system, which can provide some specific data related to the IP evaluation. We should consider situation of importance of future value for most banks when they provide the financing business, and combine the aspects including cost assessment, market assessment, technological perfection, future development direction, patent life as the basis of evaluation with market demand and use the fuzzy AHP comprehensive evaluation method to create a reasonable evaluation method for the intellectual property. Also, we should pay attention to the information management of intellectual property financing transactions, and realize the dynamic management and control of intellectual property in term of market demand changes, so as to make intellectual property transactions more efficient.

Finally, with the optimization and upgrading of the existing financing mode of intellectual property pledge in China, the market competition mechanism will promote the emergence of third-party evaluation institutions, and the intermediary sector will become an effective bridge to connect departments and organizations. In this model, small and medium-sized enterprises apply for pledge financing projects by themselves, and the third-party intermediaries act as important guarantors to reasonably review the amount of financing and development prospects [8]. When the examination is qualified, a preliminary agreement can be signed. After internal bank review, financing loans are issued. The third-party management department supervises the use of enterprise funds and so on. If there are significant risks in the process of enterprise development, the third-party organization can reimburse them and sell the pledged intellectual property.

\section{References}

1. Intellectual Property Financing ----- An Introduction, Available: http://www.wipo.int/wipo_magazine/en/2008/05/article_0001.html

2. Gerald B. Halt, Jr.John C. Donch, Jr.Amber R. StilesRobert Fesnak. Intellectual Property and Financing Strategies for Technology Startups. 2017

3. Russell L. Parr, Intellectual Property: Valuation, Exploitation, and Infringement Damages (5th Edition). New York, Wiley, 2018

4. Shi Danqing and Zhang Yijing, "Constructing the application of 'safe haven' and 'notice-removal' rules in ecommerce platform from the perspective of indirect infringement of intellectual property rights," Legal system and society, vol.27 64-67, 2018.

5. Gao Jian, "Brief analysis on the problems and solutions of patent pledge financing for technology-based SME," Shanxi Science and Technology, vol. 33, no.5, pp. 24-26,2018

6. Xu Shi, "The experience and Enlightenment of American network platform undertaking indirect infringement liability of intellectual property," Northern Law, vol.05, pp. 71-79, 2018

7. Xu Di and Li Bing, "Evolutionary Game Analysis of Intellectual Property Pledge Financing Model: From the Perspective of Supply Chain Finance," Journal of Beijing University of Posts and Telecommunications (Social Science Edition), vol.20, no.04, pp. 36-43,2018

8. Xue Wenhua, "Path Setting and Risk Control Analysis of Intellectual Property Pledge Financing in Enterprise Group Finance Company," Science and Technology Economic Guide, vol.26, no.19, pp. 247,2018 